\title{
Parametric study of I-shaped shear connectors with different orientations in push-out test
}

\author{
Farid Boursas, Djamel Boutagouga \\ Laboratory of Mine, Department of civil engineering, University of Tébessa, Algeria \\ farid.boursas@univ-tebessa.dz,d.boutagonga@yahoo.fr
}

ABSTRACT. A great deal of research has been conducted to improve the understanding of the behavior of new types of shear connectors. This article presents the study of I-shaped connectors behavior under monotonic load welded in four different orientations in order to get the position which gives the high shear strength and the best ductility. For this purpose, eight push-out test specimens with I-shaped shear connectors with different orientations and dimensions were tested in C20/25 and C30/37 concrete classes. The load-slip behavior and failure modes of the tested connectors are presented and discussed. Furthermore, a non-linear 3D finite element modelling of the pushout test is performed in order to further investigate the influencing parameters on the I-shaped connectors behavior. Hence, a parametric study is carried out by using the established 3D finite elements model to study the influence of concrete strength, connector's steel grade, reinforcements, height and length

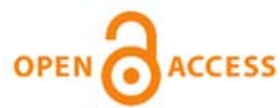

Citation: Boursas, F., Boutagouga, D., Parametric study of I-shaped shear connectors with different orientations in push-out test, Frattura ed Integrità Strutturale, 57 (2021) 2439.

Received: 26.02 .2021

Accepted: 18.04 .2021

Published: 01.07.2021

Copyright: (C) 2021 This is an open access article under the terms of the CC-BY 4.0, which permits unrestricted use, distribution, and reproduction in any medium, provided the original author and source are credited.

\section{INTRODUCTION}

$\mathrm{N}$ owadays, steel-concrete composite structures are increasingly used in many structural applications. These structures combine the steel and concrete materials to extract their best performances through the adequate coupling of these materials into an integral cross-section. By the rational structural use of the right materials at the right places, mixed beams can offer highly efficient and lightweight units commonly used in structures like multi-story buildings and large-span bridges. The composite behavior of these structures is largely influenced by the amount of interfacial slip. In order to limit the slip between steel and concrete, both materials are mechanically joined together using 
mechanical connection elements, known as connectors. Consequently, the behavior of composite beams is greatly affected by shear connectors strength and ductility.

In practice, several forms of shear connectors are widely used. However, only few are proposed in the Eurocode 4 [1], therefore, Push-out tests are used in order to study the behavior of shear connectors and their efficacity. Shear connectors are generally divided into two classes, rigid, and flexible "ductile" connectors depending on the distribution of shear forces and the functional relationship between force and interfacial slip [2]. Note that, the various studies carried out on shear connectors for more than 50 years, have shown that there is no ideal connector [3]. The choice of this or that type of connector depends on the cost, the implementation difficulties, and the mechanical performances of the connector. Several research works have focused on studying new types of shear connectors that can be used instead of the ones proposed by Eurocode 4 [1]. It was revealed that these new shear connectors offer better resistance, structural safety, welding quality, constructability, cost-effectiveness, etc.

The V-shaped angle shear connector [4], for instance, exhibits several satisfactory proprieties such as ductility, elevated resistance, high shear transmission, and it is more economical than other shear connectors [4]. The newly suggested Lshaped, C-shaped, and I-shaped shear connectors [5-7] can efficiently provide adequate mechanical performances. Furthermore, high-strength friction-grip bolts were proposed as shear connectors [8]. They can be easily unbolted during deconstruction and structural modification. Another new shear connector is developed from the reforming of a part of the steel section flange to be embedded inside the concrete to resist slippage between steel and concrete [8]. Hollow steel tube (HST) shear connectors and web opening (WO) shear connectors were also studied [9]. It should be also noted that the steel pipe has been recently studied as a new shear connector [10].

Experimental push-out tests are expensive and time-consuming. That is why reliable numerical modeling can be a good alternative to experimental tests. Finite Element models of the push-out test have been developed to investigate the bearing capacity of shear connectors in many research works.

Timber-concrete composite beams under long-term loading has been modeled by Fragiacomo and Ceccotti [11]. All anomalies affecting the long-term behavior of timber, concrete and the attachment system, such as creep, mechano-sorptive creep, shrinkage/swelling and variations in temperature were considered. Another model using the finite element software ANSYS was proposed by Queiroz et al [12]. The proposed FE model can simulate the whole Flexural loadings of composite beams which are subject to simple support. its covers Load-deflection behavior, longitudinal slip at interface between the steel and concrete, stud shear force distribution, and modes of failure. Nguyen and Kim [13] developed a finite element model of the push-out test to investigate the load capacity of large stud shear connectors. The material nonlinearities of concrete, steel beam, headed studs, and rebar were included in the finite element model. A parametric FEM analysis was carried out by Xu and Sugiura [14] to investigate "the mechanical performances of group studs", in which, damage plasticity was introduced to simulate material nonlinear behavior of concrete. In order to study composite beams with profiled sheeting oriented perpendicularly to its axis, a three-dimensional nonlinear finite element model was established in [15]. The push-out test analysis was performed using ABAQUS/Explicit with a very slow load program to guarantee a quasi-static solution. An elasto-plastic behavior was used for all steel components while the Concrete Damaged Plasticity model was adopted for the concrete slab [15]. A three-dimensional quarter-scale finite element model for headed stud connectors pushout test was developed by Bouchair et al [16] using the software ATENA. Han et al [17] used damage plasticity model for concrete and contact algorithms available in ABAQUS software to numerically investigate composite beams with crumb rubber concrete slabs. Paknahad et al [18] recently estimated experimentally and analytically the effect of high-strength concrete (HSC) on the shear capacity of the channel shear connectors (CSC) in the steel concrete composite floor system [18].

An interesting connector type known as an "I-shaped" shear connector was tested under static loading [7,19]. The test results show that in composite beams, I-shape connectors can be used to transfer the longitudinal shear forces and limit the interfacial slippage between the steel and concrete. In these works, the lowest inertia of the I-shaped connector was employed to resist the interfacial shear force. Indeed, in the previous works, the I-shaped connector was oriented in the way that its axis of lowest inertia was against shear force action axis, see Fig. (1). As the I-shaped shear connector has three distinct principal axes of inertia, it can take several orientations within the concrete slab, which can offer different stiffness and ductility, which can be more advantageous in resisting the interfacial slip and shear forces. Therefore, this work aims to investigate the I-shaped shear connector load-slip behavior when the I-shaped connector takes different orientations in the concrete slab plane. Several experimental tests and numerical analysis were performed in order to attain the best orientation that gives the superior shear strength. We have also investigated, in this study, the main influential factors on the behavior of the I-shaped connectors. 


\section{EXPERIMENTAL PROGRAM}

he main idea of this work is to test I-shaped steel shear connectors in different orientations within the concrete slab relative to the steel beam axis, which is, the main axis of action in a steel-concrete mixed beam.

This section is devoted to highlight the undertaken experimental program, describe the tested push-out specimens, and test set-up.

\section{Specimens presentation}

Four orientations of the connector axes relative to the steel beam longitudinal axis as shown in Fig. (1) are investigated in this study.

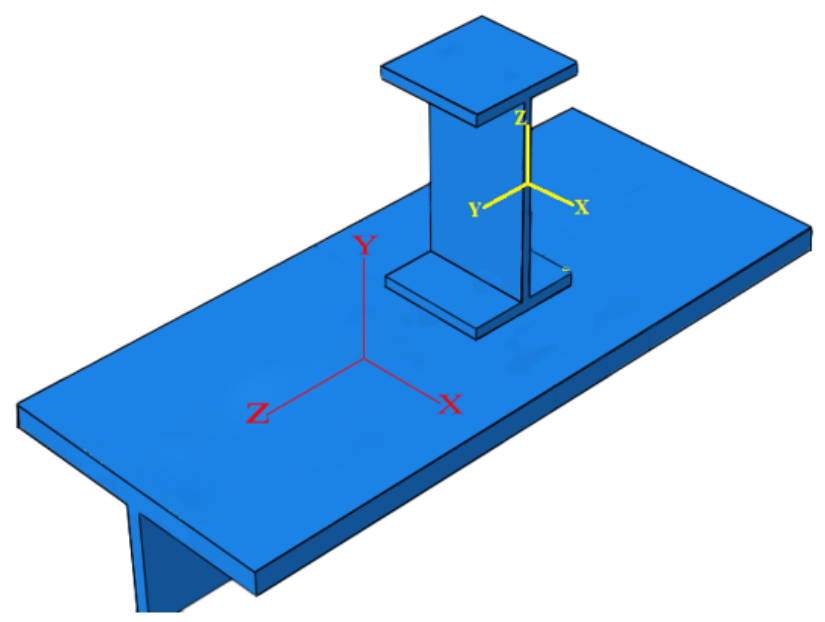

(a) P01

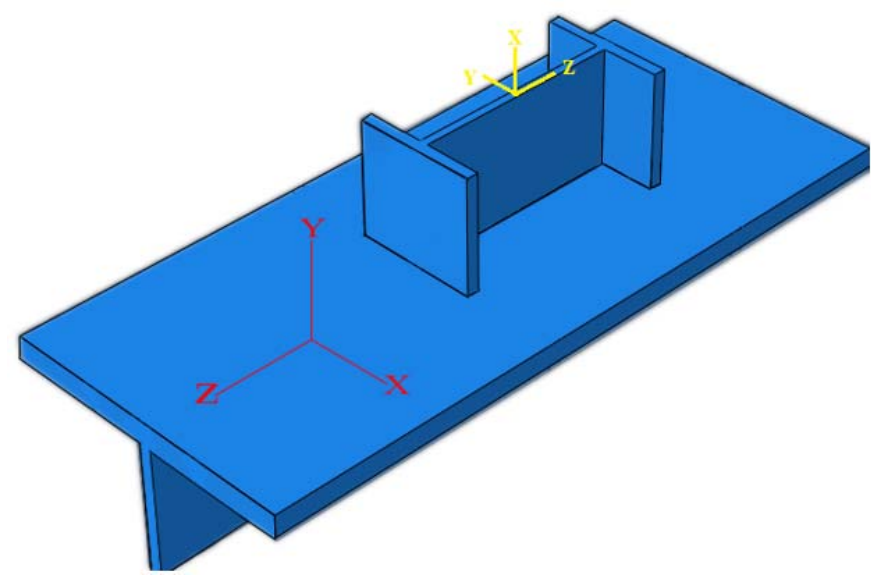

(c) P03

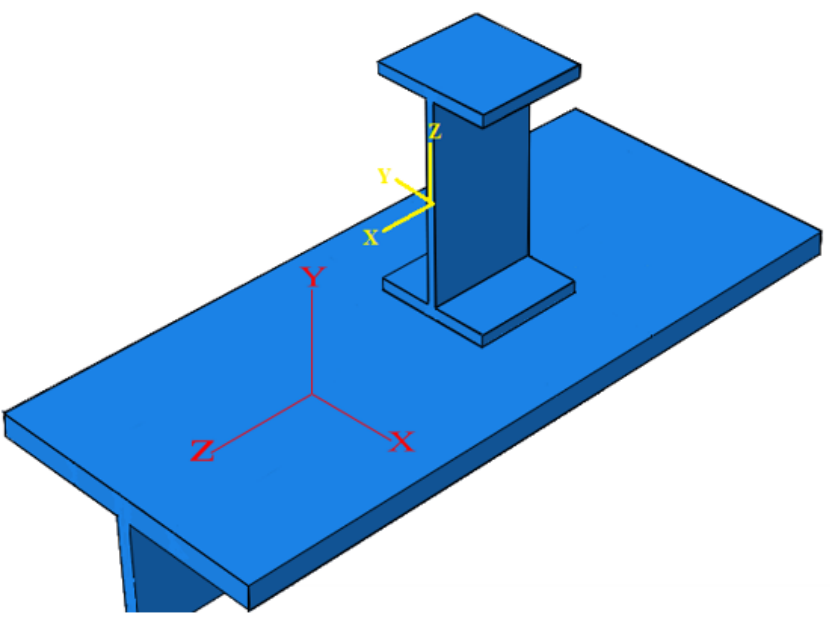

(b) P02

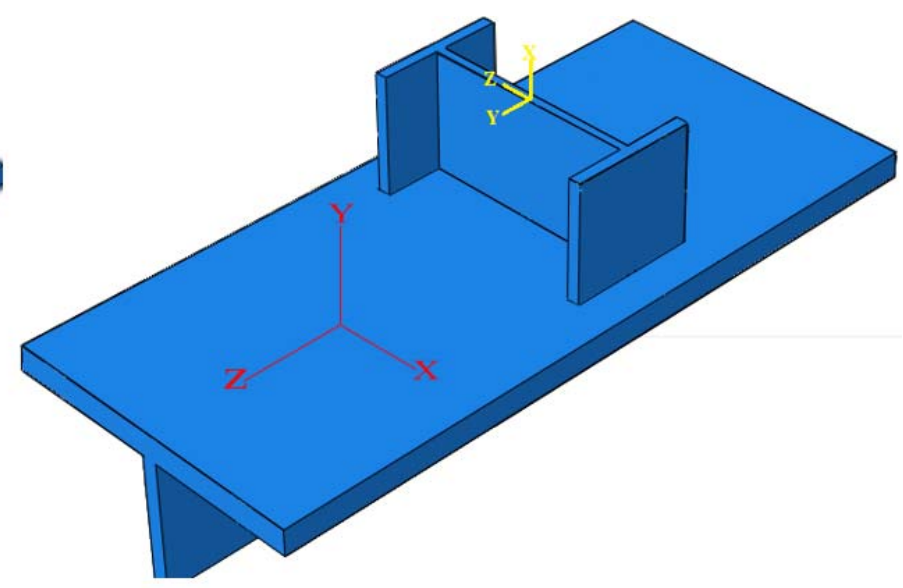

(d) P04

Figure 1: The I-shaped connector in different configurations

In this study, the composite beam is composed by an HEB160 steel beam connected to a concrete slab of dimensions $\left(36 \times 32 \times 12 \mathrm{~cm}^{3}\right)$ reinforced by 4 rebars of $8 \mathrm{~mm}$ in diameter so $4 \Phi 8$ in both directions, as shown in Fig. (2). The connection is made up by means of an IPE120 shear connector.

The standard dimensions according to Eurocode 4 of the whole specimen [1] are presented in Fig. (3). Two concrete classes $\mathrm{C} 20 / 25$ and C30/37 that correspond to the desired compressive strengths of $20 \mathrm{MPa}$ and $30 \mathrm{MPa}$ respectively were adopted 
in this study for the push-out tests. We adopted the steel grade S355 ( $\mathrm{fy}=355 \mathrm{MPa}$ ) for the HEB160 steel beam and S235 $(\mathrm{fy}=235 \mathrm{MPa})$ for the IPE120 steel connectors.
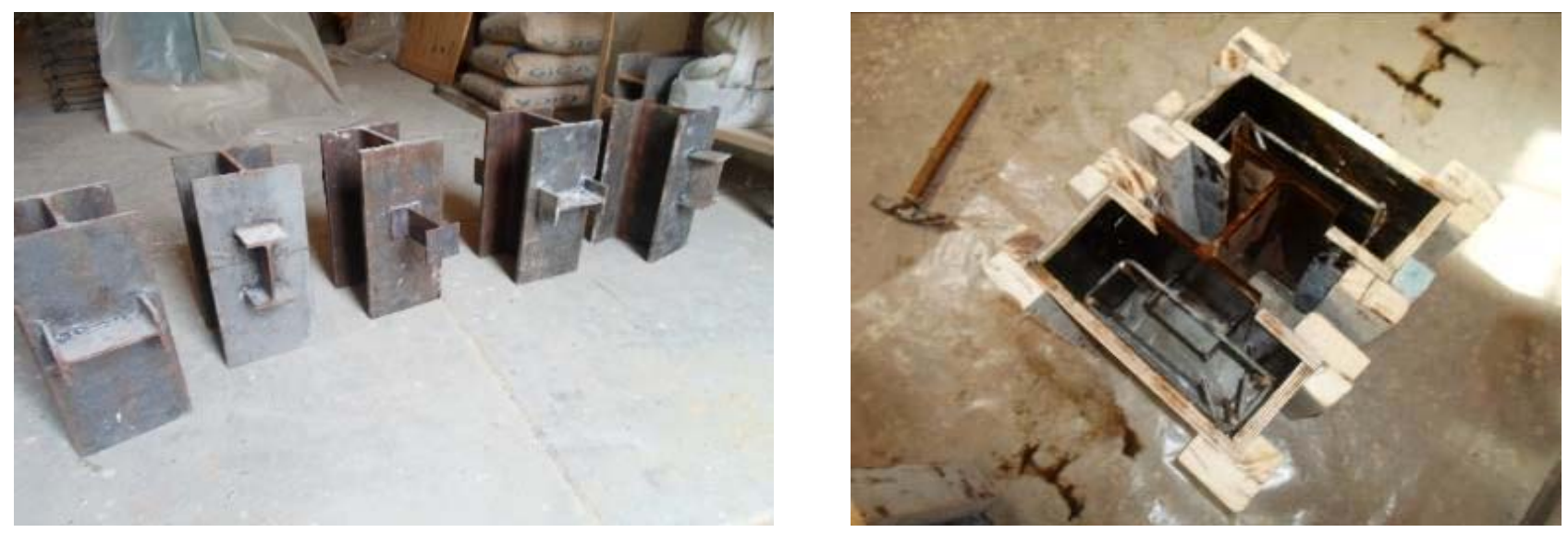

Figure 2: Push-out specimens' preparation.
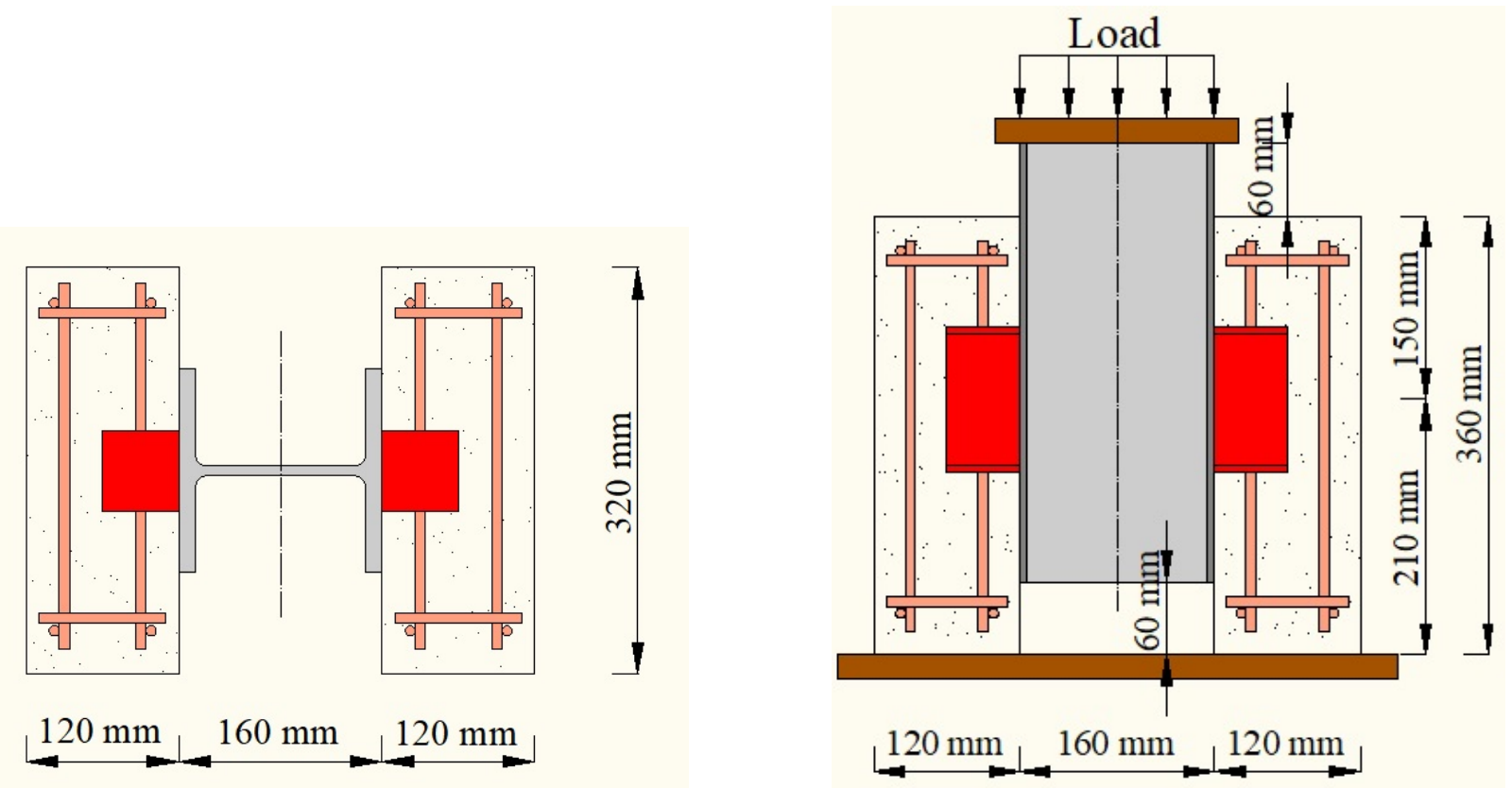

Figure 3: Dimensions and details of the push-out specimens in the configuration P03.

\section{Material properties}

Two steel tensile coupon specimens were taken out from The IPE120 flange and web in order to determine the stress-strain curve of the IPE120 connector through standard tensile testing of the taken coupons. The dimensions of the specimen are taken according to ISO 6892-1 [20].

The obtained material properties, including the yield stress, the ultimate tensile stress and Young's modulus of elasticity of the IPE120 connector, are listed in Tab. (1).

\begin{tabular}{cccc}
\hline Type & fy (MPa) & fu (MPa) & E (MPa) \\
IPE120 flange plate & 217 & 352 & 205000 \\
IPE120 web plate & 248 & 368 & 208000 \\
\hline
\end{tabular}

Table 1: Mechanical properties of the connector's steel. 
In this study, two desired compressive strengths of $20 \mathrm{MPa}$ and $30 \mathrm{MPa}$ for the concrete slab were obtained using a plasticizer adjuvant as water reducer. These two classes of concrete were formulated by using the DREUX-GORISSE method [21]. The used concrete mixes are listed in Tab. (2).

\begin{tabular}{ccc}
\hline Concrete mixes component & C20/25 & C30/37 \\
Gravel (3/8) & $263.111 \mathrm{~kg}$ & $263.111 \mathrm{~kg}$ \\
Gravel (8/15) & $708.117 \mathrm{~kg}$ & $708.117 \mathrm{~kg}$ \\
Sand & $630.937 \mathrm{~kg}$ & $630.937 \mathrm{~kg}$ \\
Cement & $350 \mathrm{~kg}$ & $350 \mathrm{~kg}$ \\
Water & 208.5381 & 157.1501 \\
Super plasticizer & 5.251 & 5.251 \\
\hline
\end{tabular}

Table 2: The concrete mixes.

In order to avoid the disparity of concrete compressive strength from one slab to another, the slabs of all the push-out specimens were cast vertically; the friction effect at the steel-concrete interface was eliminated by oiling the steel flanges before casting the slabs. During the concrete cast of the push-out specimens, four concrete cylinders of $160 \mathrm{~mm}$ in diameter and $320 \mathrm{~mm}$ of length were casted from the concrete mixture. These concrete specimens were tested for compressive strength on the same day of the push-out tests. The experimental program considers eight push-out specimens. All the tested specimens are shown in the Tab. (3).

\begin{tabular}{cccc}
\hline Series & Specimens & Fc (MPa) & Average Fc (MPa) \\
Serie A & P01-A & 21.980 & \\
& P02-A & 19.538 & \\
& P03-A & 20.077 & 20.487 \\
P04-A & 20.354 & \\
Serie B & P01-B & 28.882 & 30.037 \\
& P02-B & 29.435 & \\
& P03-B & 30.143 & \\
\hline
\end{tabular}

Table 3: The obtained concrete compressive strength.

\section{Test Setup}

A concentrated monotonic loading is applied at the top of the HEB160 cross section of the push-out specimens, as shown in Fig. (4). The load is applied using a calibrated hydraulic jack connected with an electric hydraulic pump. The capacity of hydraulic jack is $500 \mathrm{kN}$. The relative displacements between the HEB160 steel section and the concrete slab is measured using a linear variable differential transformer (LVDT) connected with data acquisition system installed at the top center of HEB160 web to measure the relative displacement between the connector and the HEB160 top which is the total displacement applied during the push-out test. Two rigid steel plates of $20 \mathrm{~mm}$ thickness were used as base plates during the test. One of theme was placed between the HEB160 steel section and the hydraulic jack in order to distribute the applied load on the whole HEB160 transverse section. The second one was placed under the concrete slabs to serve as a rigid base. The test was carried out in accordance with Eurocode 4 [1]. The load was applied in increments of $10 \mathrm{kN}$ from 0 to $100 \mathrm{kN}$ ( $40 \%$ of the expected failure load), then returned back to $12.5 \mathrm{kN} \mathrm{(5 \%} \mathrm{of} \mathrm{the} \mathrm{expected} \mathrm{failure} \mathrm{load).} \mathrm{After} \mathrm{that,} \mathrm{the} \mathrm{loading}$ cycle between $12.5 \mathrm{kN}$ and $100 \mathrm{kN}$ was repeated 25 times to remove any lack of fit in the test set up. Then, the applied load continued monotonically up to the failure. 


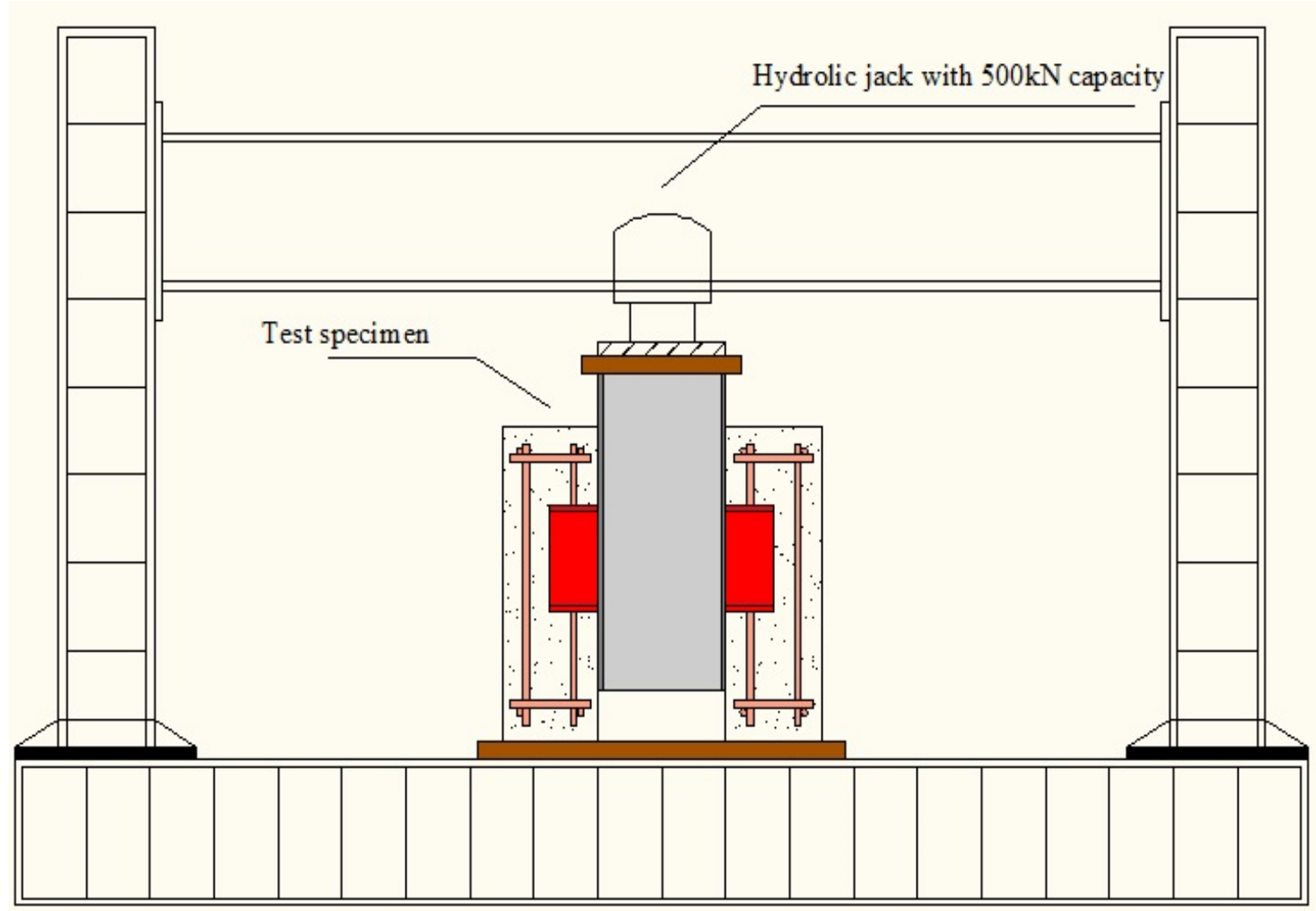

Figure 4: Test setup.

\section{Experimental results}

The ultimate load (Ptest), ultimate displacement ( $\Delta$ test), failure modes, and the load-slip curves for each tested specimen are the main obtained results from the carried out experimental push-out tests. The obtained results will be presented and discussed in details in this section.

To obtain the bearing capacity of one connector (Ptest), the ultimate load carried by the two shear connectors placed on both sides (flanges) of the HEB160 steel section is divided by the number of connectors (which is two in this case). $\Delta$ test is the maximum slip recorded between the steel and concrete measured at the connector level.
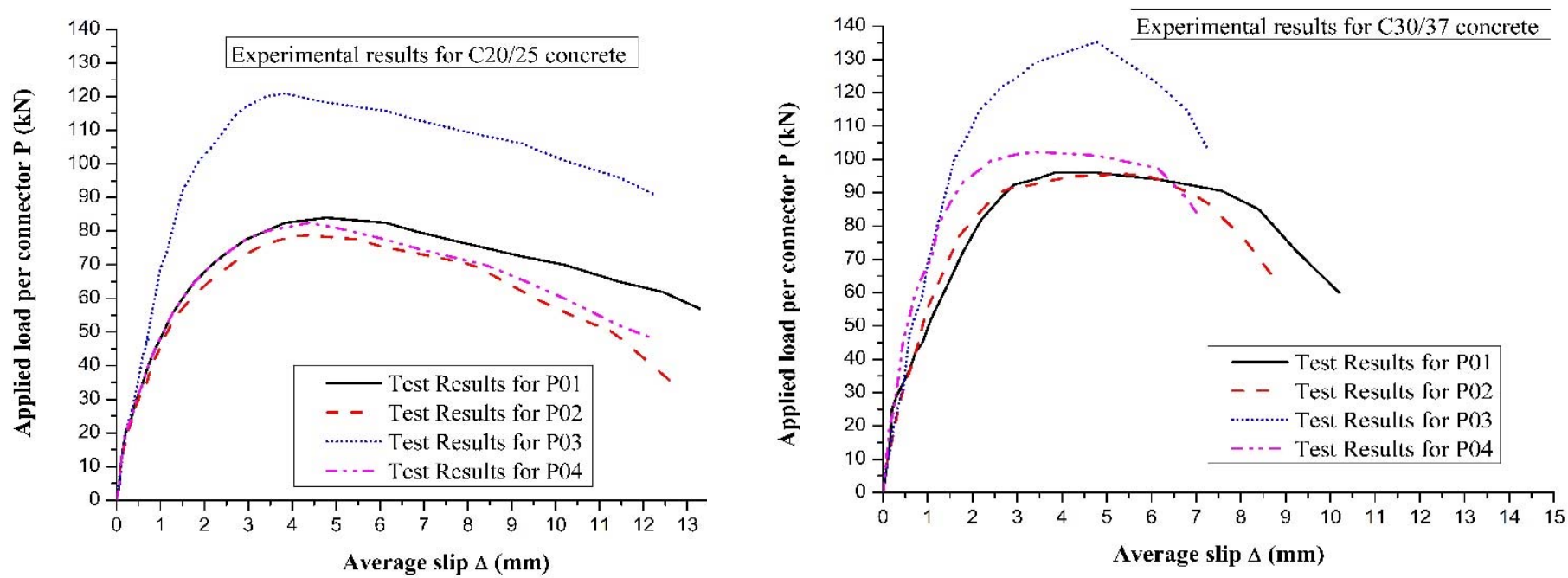

Figure 5: Experimental test results 
The obtained relationship between the applied load and the recorded interfacial slip for all tested specimens are shown in Fig. (5). It is easy to notice from the obtained results listed in Tab. 4 that there is a privilege orientation for which the shear capacity of an I-shaped connector is significantly larger than that of all other tested orientations in both concrete classes. On the other hand, with the increase of the concrete class from C20/25 to C30/37, it is observed that the ultimate load (Ptest) in configuration P01 increases by $14.28 \%$, in configuration P02 increases by $21.17 \%$, in configuration P03 increases by $11.78 \%$, and in configuration, P04 increases by $23.88 \%$. However, this increase of resistance is companied by a loss in ductility especially in the configurations P03 and P04.

\begin{tabular}{|c|c|c|c|c|}
\hline Concrete class & Positions & $\begin{array}{l}\text { shear ultimate loads } \\
\qquad(\mathrm{kN})\end{array}$ & $\begin{array}{l}\text { increment of ultimate } \\
\text { load refer to P01 } \\
\text { configuration. }\end{array}$ & Failure mode \\
\hline \multirow[t]{4}{*}{$\mathrm{C} 20 / 25$} & P01 & 84 & / & Concrete crushing \\
\hline & P02 & 78.9 & $-0.06 \%$ & Concrete crushing \\
\hline & P03 & 121 & $44.05 \%$ & Concrete crushing \\
\hline & P04 & 82.5 & $-0.01 \%$ & Concrete crushing \\
\hline \multirow[t]{4}{*}{ C30/37 } & P01 & 96 & / & Concrete crushing \\
\hline & P02 & 95.6 & $-0.00 \%$ & $\begin{array}{l}\text { Shearing of the } \\
\text { connector }\end{array}$ \\
\hline & P03 & 135.25 & $40.89 \%$ & Concrete crushing \\
\hline & P04 & 102.2 & $0.06 \%$ & Concrete crushing \\
\hline
\end{tabular}

Table 4: Shear ultimate loads and failure modes.

The obtained test results clearly show that the I-shaped connector exhibits a ductile behavior $(\Delta$ test $>6 \mathrm{~mm})$ in all the tested configurations. It is noticed from the analysis of the test results obtained with C20/25 concrete class that the maximum slip $\Delta$ test decreases by $8.95 \%$ with the change of connector orientation from the configuration P01 for which $\Delta$ test $=13.28$ $\mathrm{mm}$ to the configuration P03 for which $\Delta$ test $=12.23 \mathrm{~mm}$. A decrease of slip by $8.65 \%$ can also be noticed with the change of connector orientation from the configuration P01 to P04.

The decrease of ductility is more remarkable with C30/37 concrete class compared to the maximum slip obtained with the C20/25 concrete class, especially in P03 and P04 configurations.

The observed failure modes for the tested specimens can be classified into two types, the first one is the cracking and crushing of concrete slab, while the second is the shearing of connector with a remarkable cracking of the surrounding concrete. The first failure mode has been observed in all specimens with C20/25 concrete class as shown in Fig. (6.a). The shearing of connector was noticed in the connector orientation P02 with C30/37 concrete class. A form of shear cutting in the connector's web embedded inside the concrete as shown in Fig. (6.b).

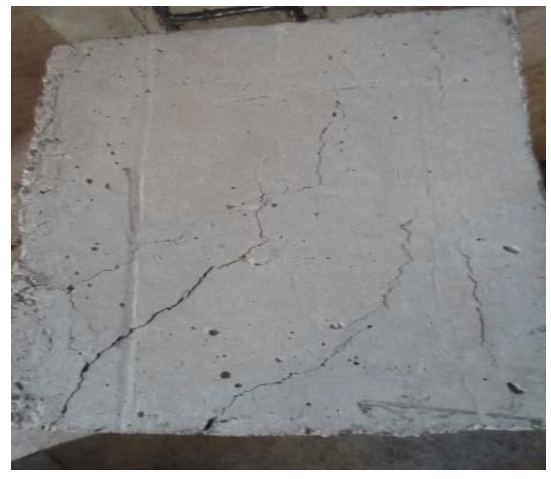

(a)

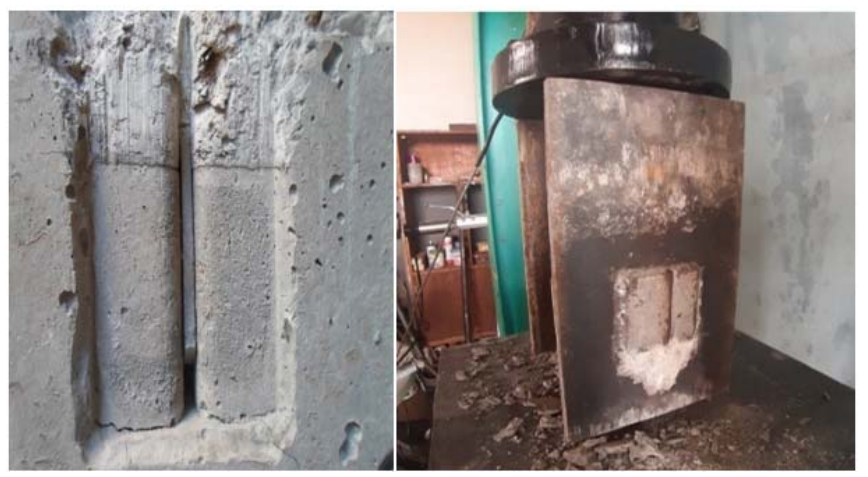

(b)

Figure 6: Failure modes. (a) Concrete crushing, (b) Shearing of the connector. 


\section{FINITE ELEMENT MODELLING}

I

$\mathrm{n}$ this study, the finite element software ABAQUS [22] was used to simulate the non-linear push-out test. In this modelling, the composite beam is composed of an HEB160 steel beam and a reinforced concrete slab of dimensions $(36 \mathrm{~cm} \times 32 \mathrm{~cm} \times 12 \mathrm{~cm})$ connected by means of an IPE120 shear connector.

In composite beams, any component (concrete slab, steel beam, rebars and shear connectors) can significantly influence the load-slip behavior of the shear connection. In order to investigate in details, the interaction mechanism arising between the steel beam and the concrete core, a 3D FE model has been established, in which, the interaction stresses arising between the I-shaped connector and the surrounding concrete were taken into account. In this model, the geometrical, material and contact nonlinearities were considered.

\section{Material constitutive models}

The nonlinear compressive and tensile stress-strain behavior of concrete is presented by an equivalent uniaxial stress-strain curve as shown in Fig. (7). The Concrete Damage Plasticity model available in ABAQUS material library was adopted to model the non-elastic behavior of reinforced concrete. This material model is suitable for modelling concrete failure and other quasi-brittle materials with strength degradation. The material dilation angle $(\Psi)$ was taken 30.5 , and the eccentricity (ع) was taken 0.1 . The ratio of biaxial compressive strength to uniaxial compressive strength $(\mathrm{fb} 0 / \mathrm{fc} 0)$ was taken as 1.16 , and tensile-to-compressive meridian ratio $(\mathrm{K})$ is 0.667 .

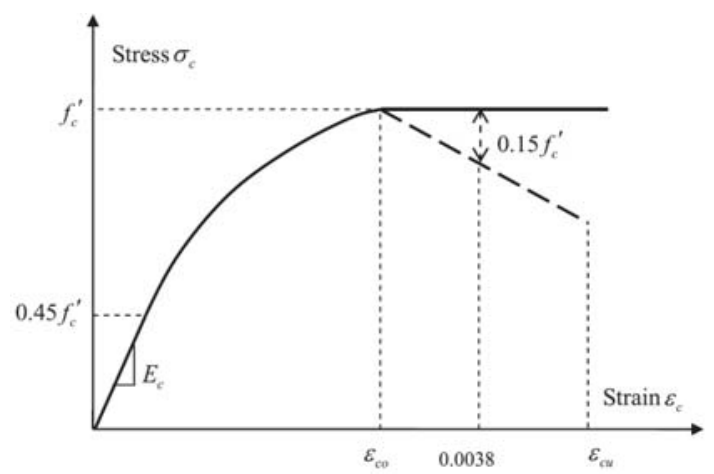

(a)

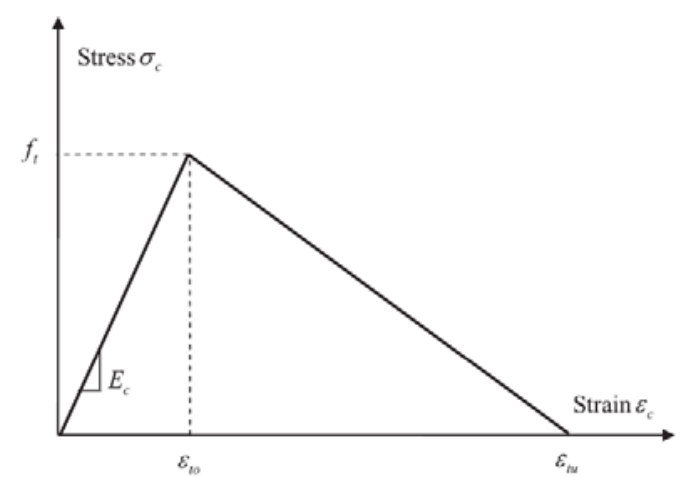

(b)

Figure 7: Stress-strain relationship for concrete [23]. (a) Compression, (b) tension.

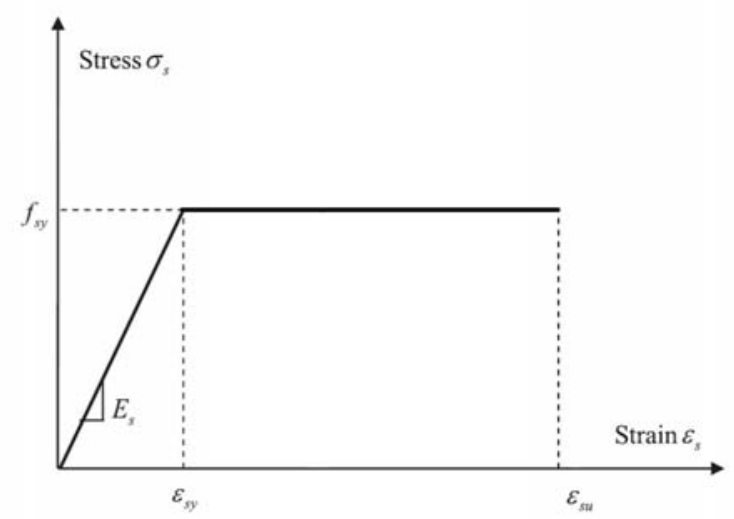

Figure 8: Stress-strain relationship Stress for I connectors, structural and reinforcement steel [24]

\section{Geometry and mesh}

Due to the symmetry of geometry, loading and boundary conditions, only one-half of the push-out test specimen was modelled as shown in Fig. (9). The numerical model of the one-half push-out specimen consists of five components, which are, one concrete slab, one half of steel beam, one I-shaped connector, reinforcement rebars and a rigid base. 


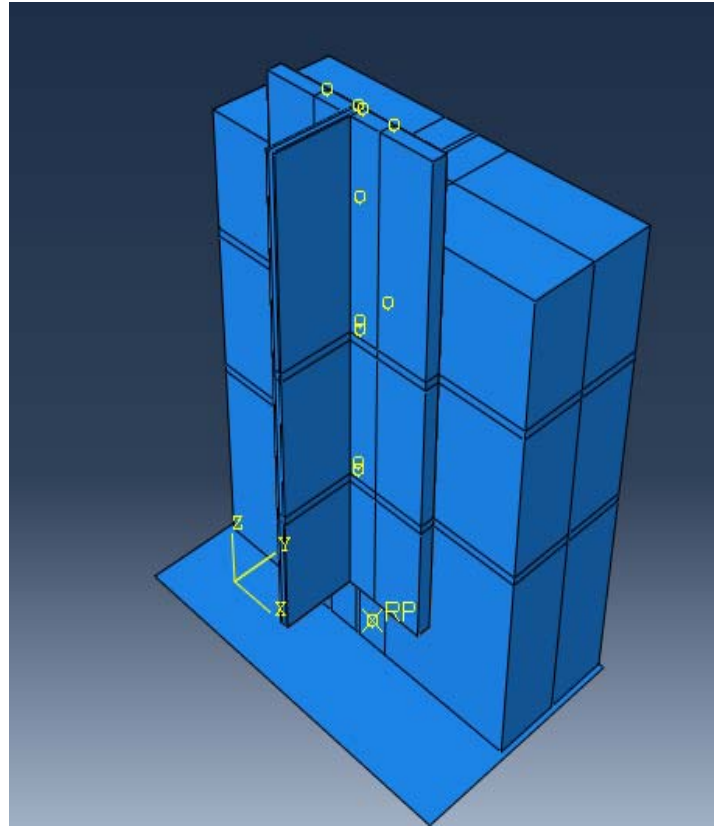

Figure 9: Push-out test specimen model

Each component was modelled as an independent part. The concrete slab, the steel beam and the I-shaped connector was modelled using the 8-node linear brick element with reduced integration "C3D8R" available in ABAQUS library [22]. This brick element can be efficiently used in nonlinear analysis including plasticity, contact, large displacements and failure. The rebar part was modelled by using the truss element T3D2, which is, a linear truss element with two nodes. The rigid base is modelled by using the discrete rigid element R3D4. In order to reduce the computational effort, a finer mesh was applied at the connector and the surrounding concrete region while, a reasonable mesh was applied to the rest of the model. in order to validate the finite element mesh of the numerical model, a mesh refinement convergence test is conducted to determine the required mesh size. An example of the finite element mesh of the modelled specimen is presented in Fig. $(10)$.

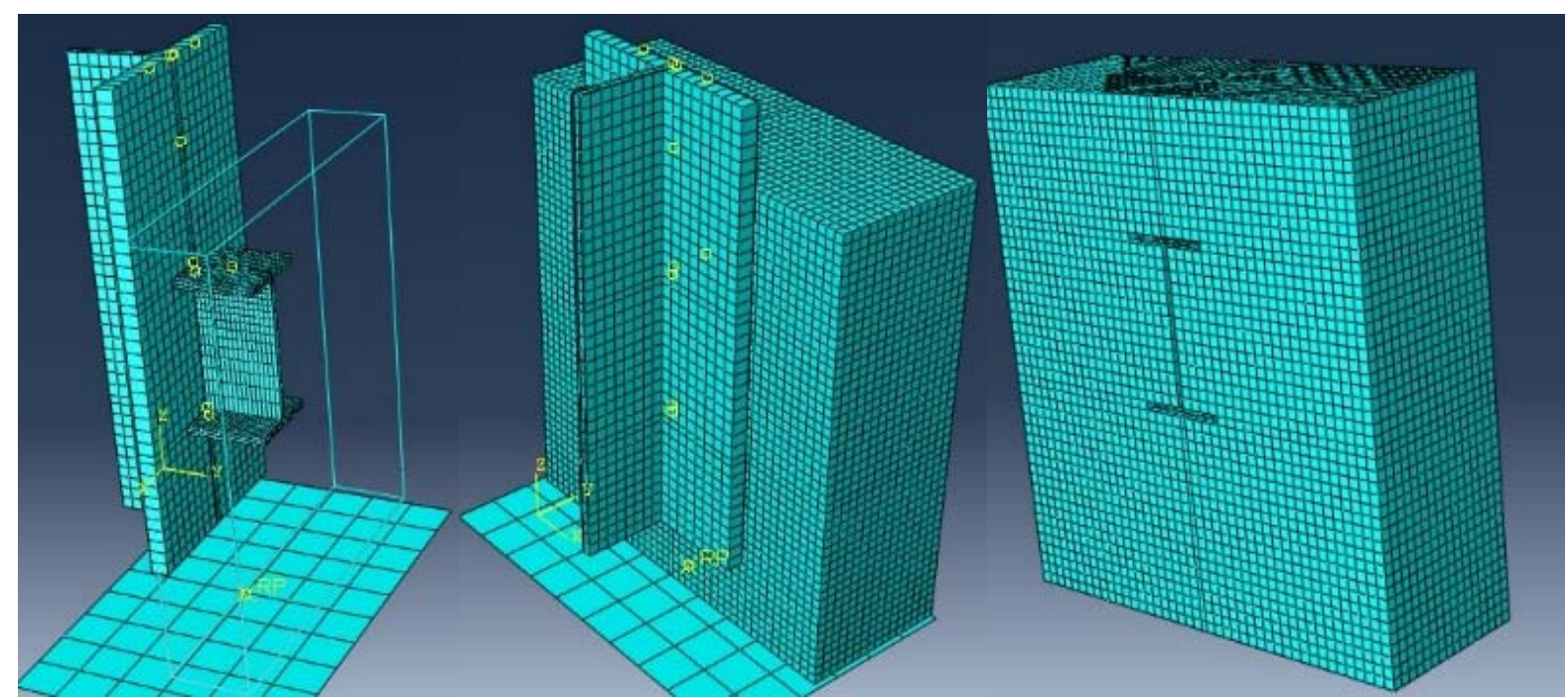

Figure 10: Finite element mesh of the specimen

\section{Interactions and constraint conditions}

The whole model was made by assembly of the five parts in their proper location. Appropriate constraints were used to describe the different interactions between components. As shown in Fig. (11), the bottom surface of the I-shaped 
connector's flange is tied to the top flange surface of steel beam. According to pushout test procedure proposed by Eurocode 4 the steel beam flange surface that is in contact with the concrete slab is greased to reduce friction resistance between them and testing only the shear resistance of the connector, in finite elements analysis, a frictionless contact interaction was applied to the steel flange and concrete slab interface.

The contact between concrete and the I-shaped connector was modelled through a contact interaction with tangential friction applied at the concrete and I-shaped connector interface. The friction coefficient value of 0.20 is adopted. The embedded-region constraint was applied to the rebars located inside the concrete slab as shown in Fig. (11). Frictionless contact interaction was applied at the interface between the concrete slab and the rigid base.

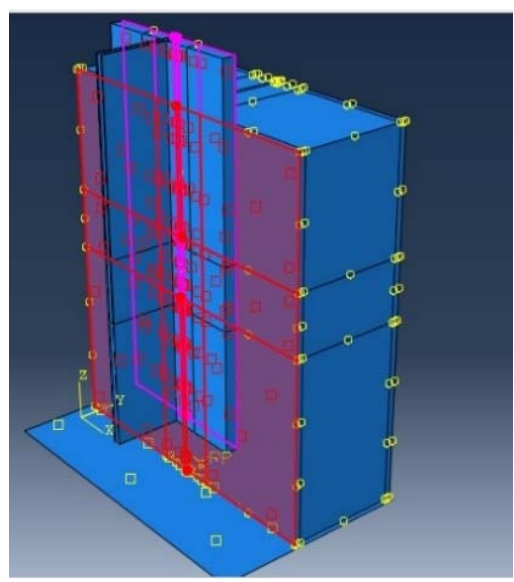

(a)

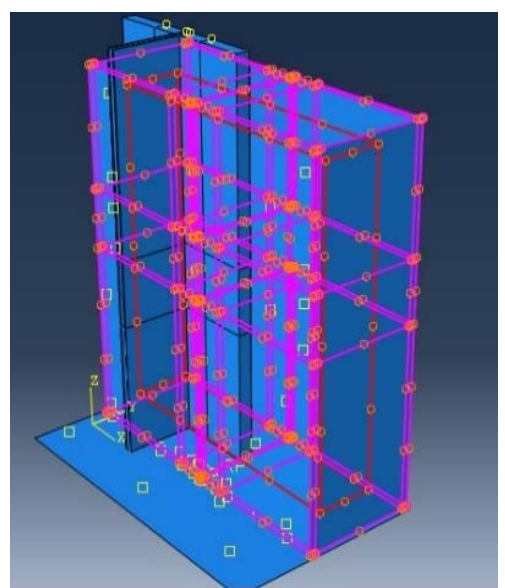

(b)

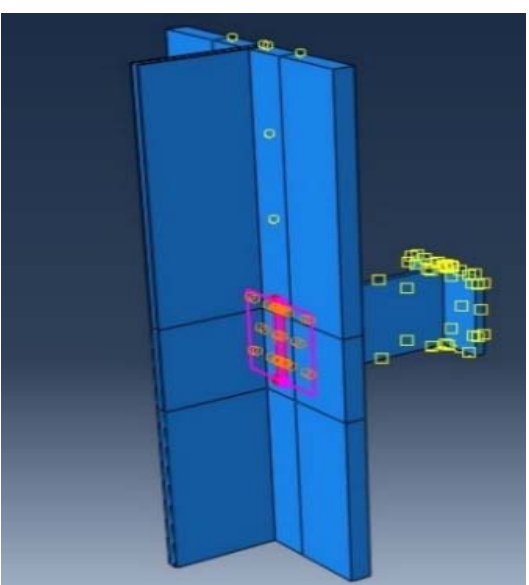

(c)

Figure 11: Interaction and constrain conditions of the specimen. (a) Interaction contact, (b) rebars embedded constraint and (c) tie constraint

\section{Loading and boundary conditions}

The symmetric boundary condition (BC) was applied to the HEB160 web's transverse section surface at the symmetry plane of the specimen as shown in Fig. (9). The rigid base was assumed to be fixed, so all DOFs of the reference point of the rigid base were restrained. In this analysis, the displacement control method was adopted in which a uniform displacement is applied to the top transverse section surface of the steel beam as shown in Fig. (12). The slip was measured as the relative displacement between the nodes on the steel flange of the I-shaped connector. The acting load was measured as the total reaction acting on the loading surface.

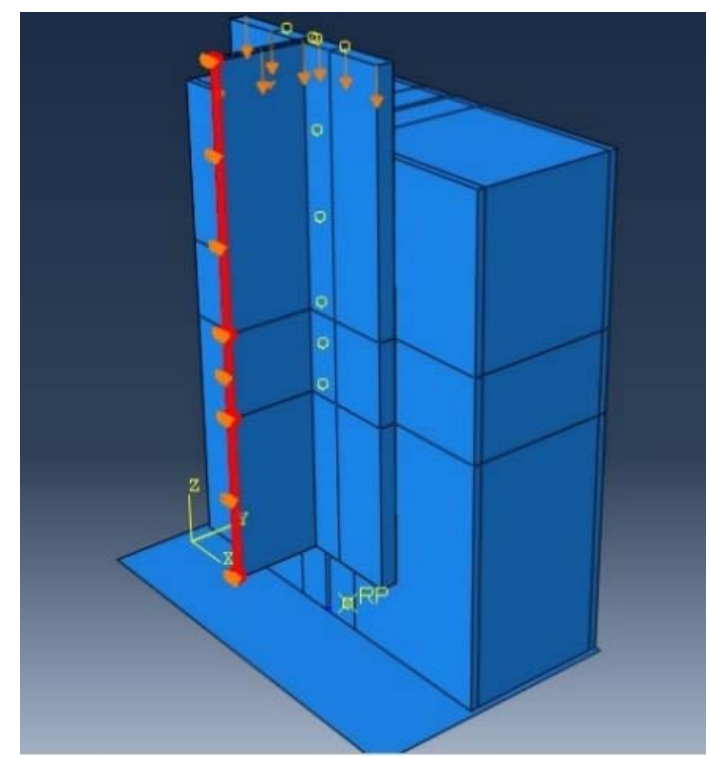

Figure 12: Symmetry and loading of the specimen. 
Finite element Results

The obtained numerical results shown in Fig. (13) were compared against the experimental test results. The comparison in Tab. (5) shows that the 3D finite element model established during this study is able to predict the ultimate shear capacity and the load-slip curve for the push-out test with I-shaped connectors efficiently.
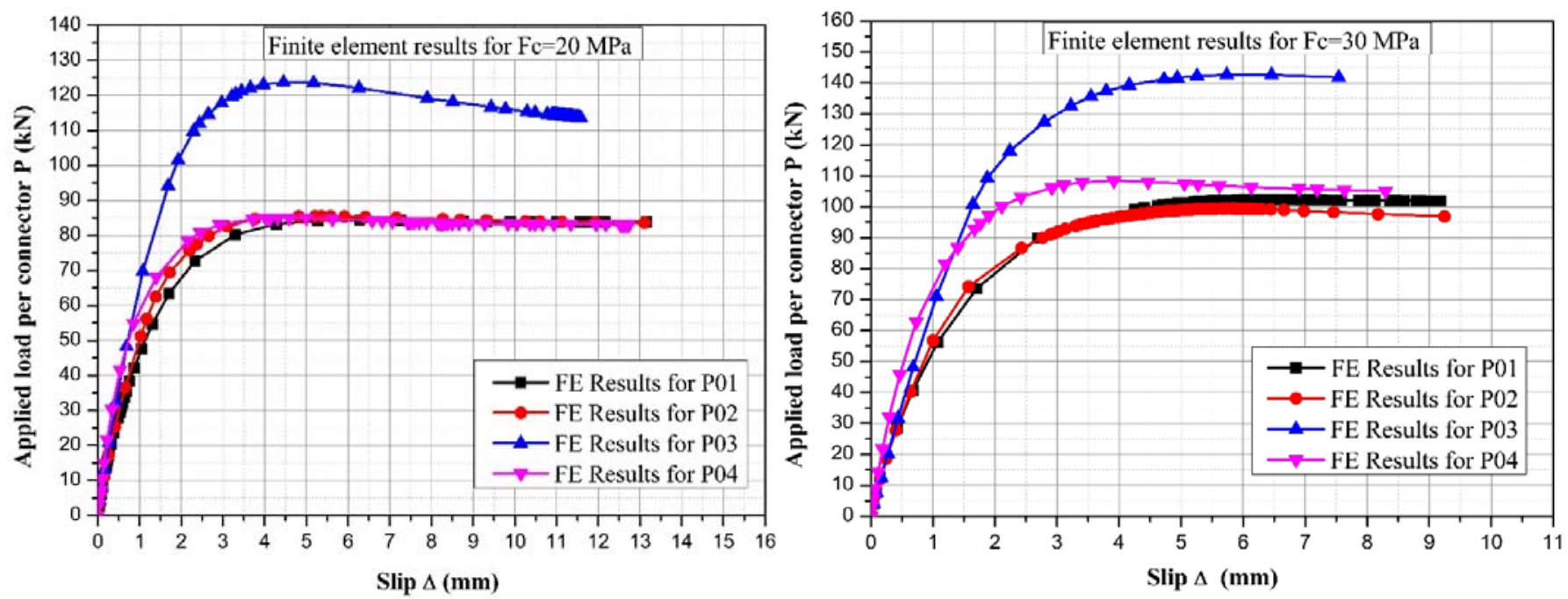

Figure 13: Finite element Results.

It is shown that in the linear regime the finite element results are in good agreement with the test results and slightly diverge from the test results in the nonlinear regime for the tests P03 and P04. However, the numerical curves take the form of plastic flow and diverge from the experimental curves after reaching the ultimate load for all specimens. This behavior can be explained by the adopted steel material behavior in the finite element model that was a bi-linear elastic perfectly plastic behavior.

Tab. (5) shows the experimental load capacity and maximum slip results versus finite elements analysis results. According to the results listed in Tab. (5), the mean values of the ratios (Ptest/PFE) and ( $\Delta$ test/ $\Delta \mathrm{FE}$ ) are 0.957 and 0.988 respectively. Stress and deformation distributions have been recorded. For instance, the stress distribution on the shear connector and on the whole model are shown in Fig. (14) for the models P01 and P03.

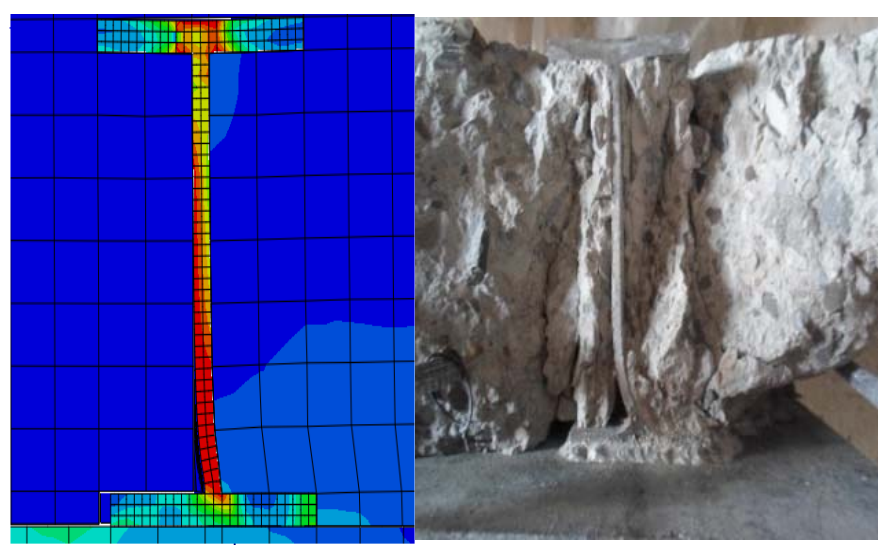

(a)
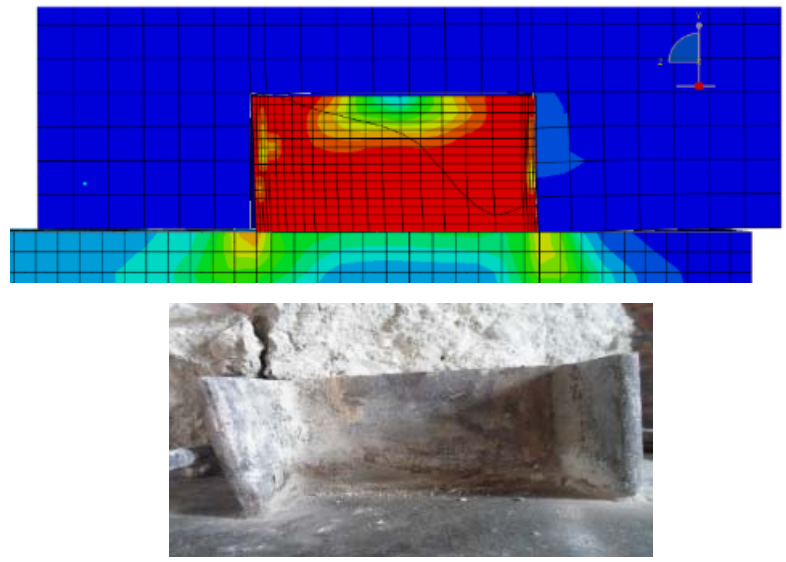

(b)

Figure 14: Stress distribution and deformations. (a) Stress distribution and deformations in P01, (b) Stress distribution and deformations in $\mathrm{P} 03$. 


\begin{tabular}{|c|c|c|c|c|c|c|c|}
\hline \multirow[t]{2}{*}{ Positions } & \multirow[t]{2}{*}{ Specimens } & \multicolumn{2}{|c|}{ Experimental results } & \multicolumn{2}{|c|}{ FE results } & \multicolumn{2}{|c|}{ Comparison } \\
\hline & & $\begin{array}{l}\text { vertical slip } \Delta \text { test } \\
\quad(\mathrm{mm})\end{array}$ & $\begin{array}{l}\text { Ultimate Load } \\
\text { Ptest (kN) }\end{array}$ & $\begin{array}{l}\text { vertical slip } \\
\Delta \mathrm{FE}(\mathrm{mm})\end{array}$ & $\begin{array}{l}\text { Ultimate Load } \\
\text { Ptest }(\mathrm{kN})\end{array}$ & $\Delta$ test $/ \Delta \mathrm{FE}$ & Ptest/PFE \\
\hline \multirow[t]{2}{*}{ P01 } & P01-A & 13.28 & 84 & 13.16 & 84.38 & 1.01 & 1.00 \\
\hline & P01-B & 10.2 & 96 & 9.17 & 102.35 & 1.11 & 0.94 \\
\hline \multirow[t]{2}{*}{ P02 } & P02-A & 13.1 & 78.9 & 13.1 & 85.46 & 1.00 & 0.92 \\
\hline & P02-B & 8.84 & 95.6 & 9.24 & 99.34 & 0.96 & 0.96 \\
\hline \multirow[t]{2}{*}{$\mathrm{P} 03$} & P03-A & 12.23 & 121 & 11.58 & 123.7 & 1.06 & 0.98 \\
\hline & P03-B & 7.28 & 135.25 & 7.54 & 142.58 & 0.97 & 0.95 \\
\hline \multirow[t]{2}{*}{ P04 } & P04-A & 12.13 & 82.5 & 12.73 & 85 & 0.95 & 0.97 \\
\hline & P04-B & 7.08 & 102.2 & 8.29 & 108.37 & 0.85 & 0.94 \\
\hline
\end{tabular}

Table 5: Comparison between Experimental results FE results.

\section{PARAMETRIC STUDY}

$\mathrm{I}$ $\mathrm{n}$ order to accomplish this study, after validating the established 3D finite elements model, certain parameters related to the push-out test such as concrete strength, connector 's steel grade, reinforcements, height and length of the connector are investigated by means of the finite elements model.

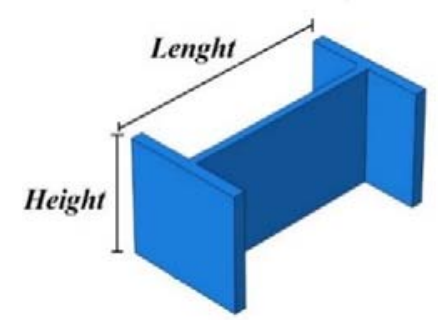

Figure 15: Evaluated parameters.

\section{Effect of the concrete compressive strength}

Three compressive strengths of concrete which are 20,30 and $40 \mathrm{MPa}$ are investigated in this study. It is observed that the increase in the compressive strength of the slab's concrete provides a considerable increase in the bearing capacity of the connector as confirmed by the experimental results, see Tab. (4).

The increase of the compressive strength of concrete from $20 \mathrm{MPa}$ to $30 \mathrm{MPa}$ provides an increase in the ultimate load capacity of the I-shaped connector from $123.70 \mathrm{kN}$ to $142.58 \mathrm{kN}$ which is approximately more than $15.26 \%$ gain in the load capacity. When the concrete strength is further increased from $30 \mathrm{MPa}$ to $40 \mathrm{MPa}$, the ultimate load capacity of I-shape connector increased by $16.52 \%$ to attain $166.14 \mathrm{kN}$. However, the gain in the load capacity is accompanied by a considerable loss in ductility. The increase of the compressive strength of concrete from $20 \mathrm{MPa}$ to $30 \mathrm{MPa}$ decreases the maximum slip from $11.58 \mathrm{~mm}$ to $7.55 \mathrm{~mm}$ which corresponds to a loss of $34.80 \%$. When the concrete strength is further increased from $30 \mathrm{MPa}$ to $40 \mathrm{MPa}$, the maximum slip decreases by $17.35 \%$ as shown in Fig. (16).

\section{Effect of the steel grade}

In order to evaluate the influence of the connector's steel grade on the ultimate load capacity of the I-shaped connector, three steel grades which are S235, S275 and S355 were investigated. Fig. (17) presents the load-slip curves of the I-shaped connector in configuration P03 with the three steel grades. It can be seen that the increase of the connector's steel grade provides a non-significative increase in the connector's load capacity. This increase of the load capacity is also accompanied by a non-significative decrease in the connector's ductility. 


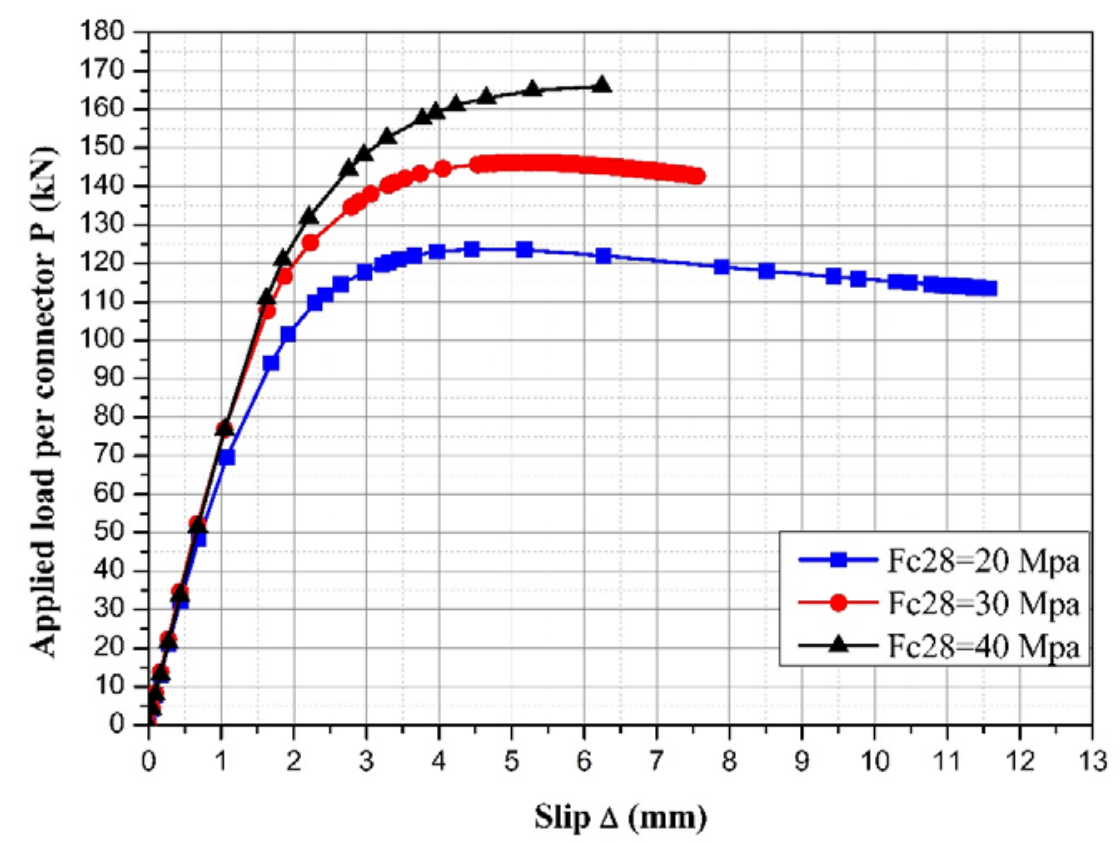

Figure 16: Effect of the concrete compressive strength

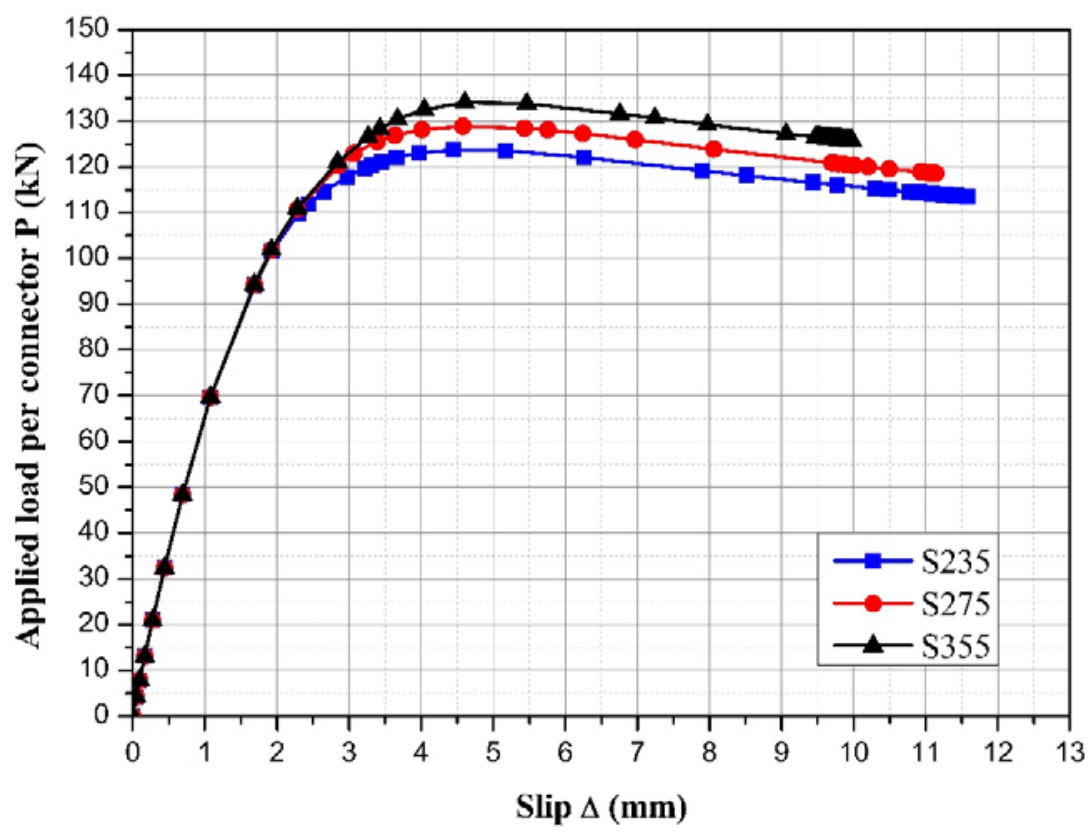

Figure 17: Effect of connectors steel grade.

\section{Effect of the height}

The influence of the height of the I-shaped connector on the ultimate load capacity is shown in Fig. (18). By increasing the connector's height from $60 \mathrm{~mm}$ up to $70 \mathrm{~mm}$, a considerable increase of the ultimate load from $123.70 \mathrm{kN}$ up to $139.50 \mathrm{kN}$ is attained. This gain represents $12.77 \%$ from the initial ultimate load. However, any further increase of the connector's height does not provide any significant increase of the ultimate load, as shown in Fig. (18). It can be easily noticed that an increase of the connector's height brings a remarkable increase of the connector's ductility. The maximum slip increases from $11.58 \mathrm{~mm}$ to $14.81 \mathrm{~mm}$ then to $17.07 \mathrm{~mm}$ when the connector's height increases from $60 \mathrm{~mm}$ to $70 \mathrm{~mm}$ then to 80 $\mathrm{mm}$ respectively, which is a $47.40 \%$ increase from the initial slip capacity. 


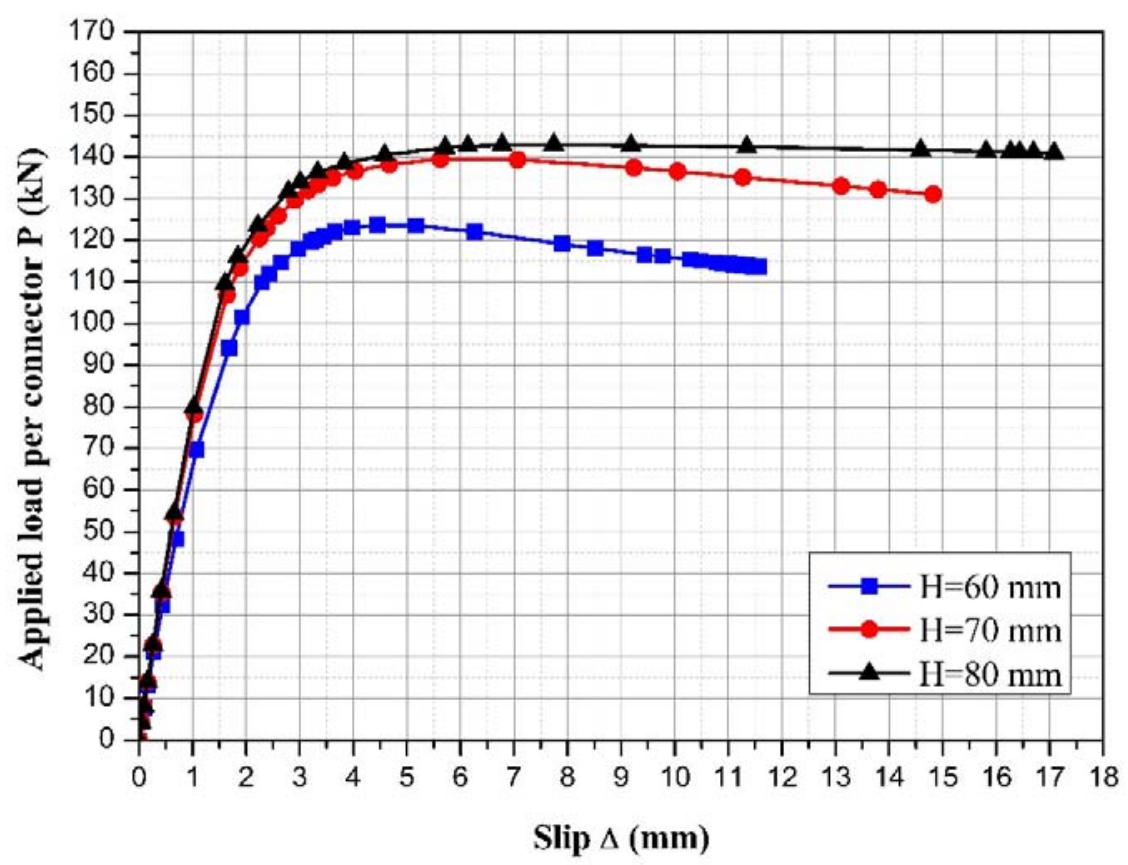

Figure 18: Effect of height.

\section{Effect of the length}

The effect of the connector's length on the ultimate load capacity is similar to the effect of the connector's height. Increasing the length from $120 \mathrm{~mm}$ up to $140 \mathrm{~mm}$ leads to an increase of $16 \%$ from the initial ultimate load. But when we increase the connector's length to $140 \mathrm{~mm}$ there is an increase of the ultimate load by18\%, as shown in Fig. (19). However, the increase of the connector's length results in a slight decrease of ductility, as shown in Fig. (19).

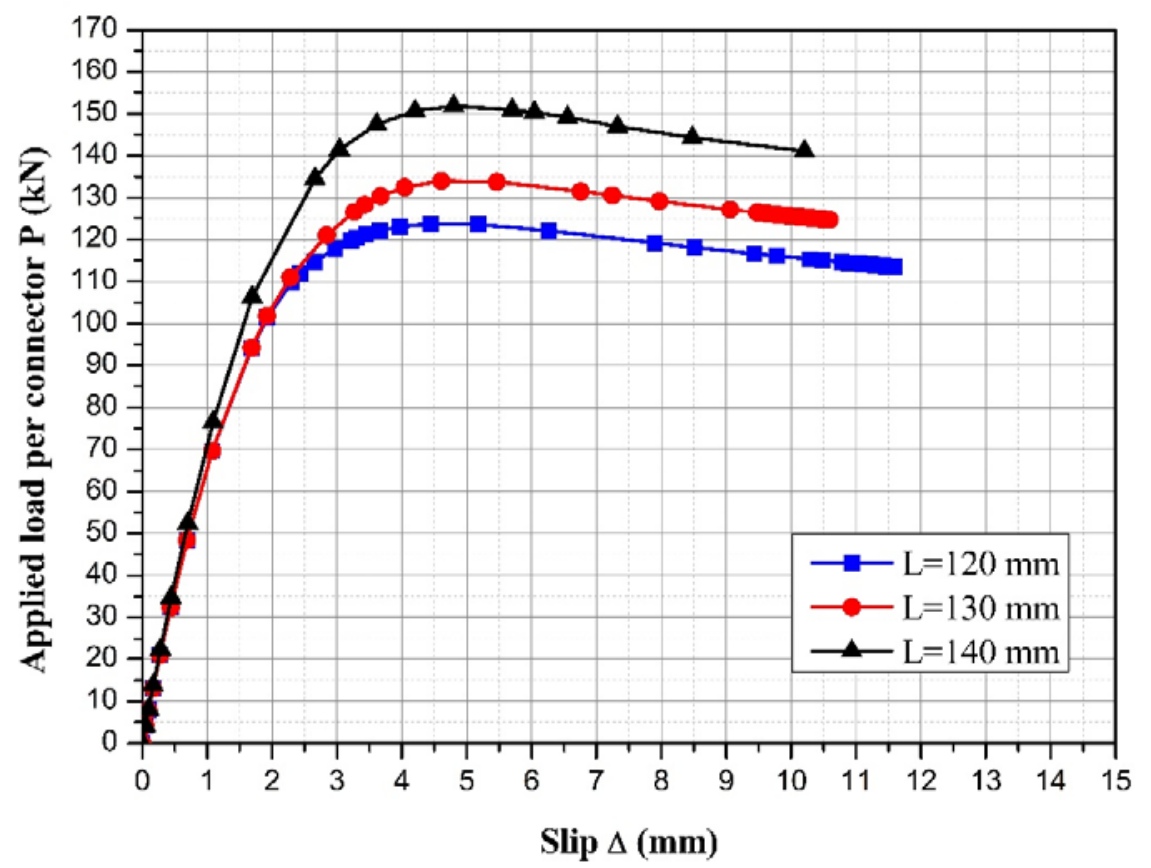

Figure 19: Effect of length

\section{Effect of concrete reinforcement}

Three diameters of reinforcement rebars $(\Phi 8, \Phi 10$ and $\Phi$ 12) were investigated in order to study the influence of this parameter on the ultimate load capacity and ductility of the I-shaped connector. It appears that a slight increase of the 
reinforcement rebars diameter yields a considerable increase in both strength and ductility. The ultimate load increased to $137.40 \mathrm{kN}$ and $139.52 \mathrm{kN}$ when using $\Phi 10$ and $\Phi 12$ rebars, respectively. At the same time, the maximum interfacial slip attains $13.39 \mathrm{~mm}$ and $14.56 \mathrm{~mm}$ respectively.

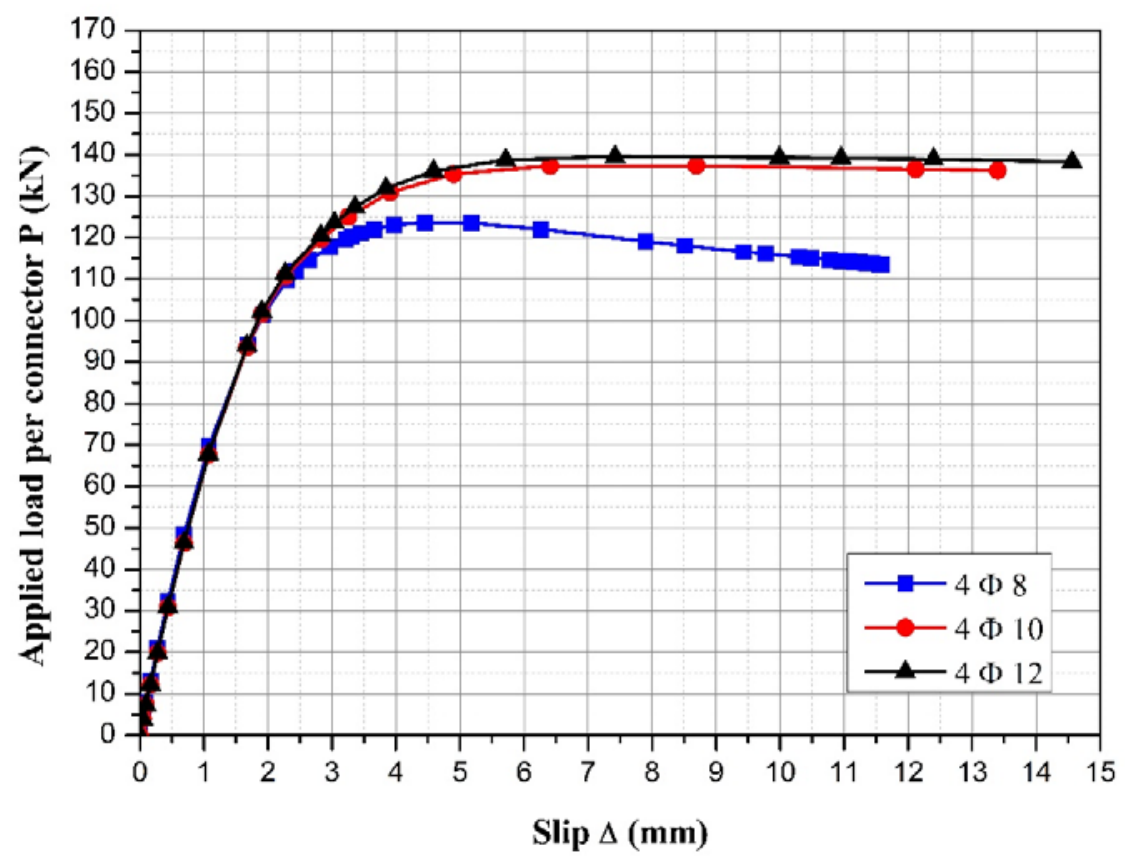

Figure 19: Effect of concrete reinforcement

\section{CONCLUSION}

$\mathrm{I}$ $\mathrm{n}$ this study, the I-shaped shear connector's behavior with different orientations in the concrete slab was investigated. Several push-out tests and finite elements modelling were conducted, in which, several influential parameters were studied. A good agreement was obtained between the finite elements' analysis and experimental tests which gives high reliability to the presented numerical parametric study.

The obtained results show that there is a privilege orientation for which the bearing capacity of an I-shaped shear connector is significantly higher than that of all other tested orientations in terms of the ultimate load capacity and interfacial slip. In this orientation, named by P03 in this study, the web surface of the I-shaped connector is parallel to the web surface of the steel beam while the flanges of the connector and the steel beam are perpendicular. Thus, the parametric study was interested by studying the effect of material and geometric parameters on the connector's behavior in this particular orientation.

According to the experimental and numerical parametric study we can conclude as follows:

- The orientation of the I-shaped connector has a significant influence on the shearing load capacity.

- The I-shaped shear connectors exhibit sufficient ductility in all the tested orientations.

- Failure was dominated by the concrete crushing failure mode.

- The steel grade of the I-shaped connector has a non-significative influence on the connector's load capacity and ductility.

- Increasing the concrete strength significantly increases the connector's load capacity. This increase of the load capacity is accompanied by a significant decrease of ductility.

- Increasing the rebars diameter, the height and the length of the I-shaped connector provides an increase of the connector's load capacity. There is a threshold from which the increasing of the rebars diameter, the height and the length of the I-shaped connector is non-significative. 


\section{REFERENCES}

[1] CEN (European Commitee for Standardization). (2004). Eurocode 4 Design of composite steel and concrete structures - Part 1.1: General rules and rules for buildings Eurocode.

[2] Rankovi, S. and Drenic, D. (2002). Static strength of the shear connectors in steel-concrete composite beams regulations and research analysis, Facta Universitatis, 2(4), pp. 251-259.

[3] Loubna, B. (2005). Contribution à l'étude expérimentale et théorique de structures mixtes acier-béton assemblées par collage. Université de Reims Champagne Ardenne, Ecole doctorale Sciences Technologies Santé.

[4] Mansouri, I., Shariati, M., Safa, M., Ibrahim, Z., Tahir, M.M., Petković, D. (2019). Analysis of influential factors for predicting the shear strength of a $\mathrm{V}$-shaped angle shear connector in composite beams using an adaptive neuro-fuzzy technique, J. Intell. Manuf., 30(3), pp. 1247-1257, DOI: 10.1007/s10845-017-1306-6.

[5] Kim, Y.H., Cho, H., Lee, S., Yoon, S.J. (2011). Experimental and analytical investigations on the hat shaped shear connector in the steel-concrete composite flexural member, Int. J. Steel Struct., 11(1), pp. 99-107, DOI: $10.1007 /$ S13296-011-1009-3.

[6] Mazoz, A., Benanane, A., Titoum, M. (2014). Push-out Tests on a New Shear Connector of I-shape, Int. J. Steel Struct., 13(3), pp. 519-28, Doi: 10.1007/s13296-013-3011-4.

[7] Titoum, M., Mazoz, A., Benanane, A., Ouinas, D. (2016). Experimental study and finite element modelling of push-out tests on a new shear connector of I-shape, Adv. Steel Constr., 12(4), pp. 487-506, DOI: 10.18057/IJASC.2016.12.4.7.

[8] Liu, X., Bradford, M.A., Chen, Q.J., Ban, H. (2016). Finite element modelling of steel-concrete composite beams with high-strength friction-grip bolt shear connectors, Finite Elem. Anal. Des., 108, pp. 54-65, DOI: 10.1016/j.finel.2015.09.004.

[9] Baharom, S., Hosseinpour, E., Badaruzzaman, W.H.W. (2018).Hollow Steel Tube Versus Web Opening As Shear Connectors in Hollow Steel Tube Versus Web Opening As Shear Connectors in Slim-Floor Steel Beam. 13th International Conference on Steel, Space and Composite Structure, Perth, Australia.

[10] Nasrollahi, S., Maleki, S., Shariati, M., Marto, A., Khorami, M. (2018). Investigation of pipe shear connectors using push out test, Steel Compos. Struct., 27(5), pp. 537-543, DOI: 10.12989/scs.2018.27.5.537.

[11] Fragiacomo, M., Ceccotti, A. (2006). Long-Term Behavior of Timber-Concrete Composite Beams. I: Finite Element Modeling and Validation, J. Struct. Eng., 132(1), pp. 13-22, DOI: 10.1061/(asce)0733-9445(2006)132:1(13).

[12] Queiroz, F.D., Vellasco, P.C.G.S., Nethercot, D.A. (2007). Finite element modelling of composite beams with full and partial shear connection, J. Constr. Steel Res., 63(4), pp. 505-521, DOI: 10.1016/j.jcsr.2006.06.003.

[13] Nguyen, H.T., Kim, S.E. (2009). Finite element modeling of push-out tests for large stud shear connectors, J. Constr. Steel Res., 65(10-11), pp. 1909-1920, DOI: 10.1016/j.jcsr.2009.06.010.

[14] Xu, C., Sugiura, K., Wu, C., Su, Q. (2012). Parametrical static analysis on group studs with typical push-out tests, J. Constr. Steel Res., 72, pp. 84-96, DOI: 10.1016/j.jcsr.2011.10.029.

[15] Qureshi, J., Lam, D., Ye, J. (2011). Effect of shear connector spacing and layout on the shear connector capacity in composite beams, J. Constr. Steel Res., 67(4), pp. 706-719, DOI: 10.1016/j.jcsr.2010.11.009.

[16] Bouchair, A., Bujnak, J., Duratna, P., Lachal, A. (2012). Modeling of the steel-concrete push-out test, Procedia Eng., 40, pp. 102-107, DOI: 10.1016/j.proeng.2012.07.063.

[17] Han, Q., Wang, Y., Xu, J., Xing, Y. (2015). Static behavior of stud shear connectors in elastic concrete-steel composite beams, J. Constr. Steel Res., 113, pp. 115-126, DOI: 10.1016/j.jcsr.2015.06.006.

[18] Paknahad, M., Shariati, M., Sedghi, Y., Bazzaz, M., Khorami, M. (2018). Shear capacity equation for channel shear connectors in steel-concrete composite beams, Steel Compos. Struct., 28(4), pp. 483-494, DOI: $10.12989 /$ scs.2018.28.4.483.

[19] Mazoz, A. (2015). Développement du système de connexion dans les poutres mixtes (acier-béton), thèse de doctorat, Université Abdelhamid Ibn Badis Mostaganem.

[20] Européenne, N. (2016). Metallic materials — Tensile testing BSI Standards Publication EN ISO 6892-1.

[21] Festa, J., Dreux, G. (2012). Nouveau guide du béton et de ses constituants, EYROLLES éditions, Paris-France.

[22] Duval, A., Al-akhras, H., Maurin, F., Elguedj, T., Duval, A., Al-akhras, H., Maurin, F., Elguedj, T. (2014). Abaqus/CAE 6.14 User's Manual, Dassault Systémes Inc. Provid. RI, USA, IV(June), pp. 1-6.

[23] Norme européenne, N. française. (2005). Eurocode 2 Calcul des structures en béton Partie 1-1: Règles générales et règles pour les bâtiments.

[24] (CEN), E.C. for S. (2005). Eurocode 3: Design of steel structures - Part 1-1 General Structure rules. 